\title{
Anorexia nervosa versus hyperinsulinism: therapeutic effects of neuropharmacological manipulation
}

This article was published in the following Dove Press journal:

Therapeutics and Clinical Risk Management

I6 February 201 I

Number of times this article has been viewed

\author{
Fuad Lechin ${ }^{1,2}$ \\ Bertha van der Dijs ${ }^{1,2}$ \\ Betty Pardey-Maldonado' \\ Scarlet Baez' \\ Marcel E Lechin ${ }^{3}$ \\ 'Sections of Neuroendocrinology, \\ Neuropharmacology, and \\ Neurochemistry, Department \\ of Pathophysiology, Institute of \\ Experimental Medicine, Faculty of \\ Medicine, Universidad Central de \\ Venezuela, Caracas; 'Instituto de Vias \\ Digestivas Caracas, Centro Clínico \\ Profesional Caracas, Venezuela; \\ ${ }^{3}$ Department of Internal Medicine, \\ Texas A \& M Health Science Center, \\ College of Medicine, Texas, USA
}

Correspondence: Fuad Lechin

Apartado 80 983, Caracas 1080-A,

Venezuela

$\mathrm{Tel}+582129611048$

Fax +582129610172

Email flechin@telcel.net.ve
Background: We have demonstrated that anorexia nervosa is underpinned by overwhelming adrenal sympathetic activity which abolishes the neural sympathetic branch of the peripheral autonomic nervous system. This physiological disorder is responsible for gastrointestinal hypomotility, hyperglycemia, raised systolic blood pressure, raised heart rate, and other neuroendocrine disorders. Therefore, we prescribed neuropharmacological therapy to reverse this central and autonomic nervous system disorder, in order to normalize the clinical and neuroendocrine profile.

Methods: The study included 22 female patients with anorexia nervosa (10 restricted type, 12 binge-eating type) who received three months of treatment with amantadine $100 \mathrm{mg} /$ day. We measured blood pressure, heart rate, and circulating neurotransmitters, (noradrenaline, adrenaline, dopamine, platelet serotonin, free plasma serotonin) during supine resting, one minute of orthostasis, and a five-minute exercise test before and after one, two, and three months of treatment with amantadine, a drug which abrogates adrenal sympathetic activity by acting at the C1(Ad) medullary nuclei responsible for this branch of the peripheral sympathetic activity.

Results: We found the amantadine abolished symptoms of anorexia nervosa from the first oral dose onwards. Normalization of autonomic and cardiovascular parameters was demonstrated within the early days of therapy. Abrupt and sustained increases in the plasma noradrenaline:adrenaline ratio and disappearance of abnormal plasma glucose elevation were registered throughout the three-month duration of the trial. Significant and sustained increases in body weight were documented in all cases. No relapses were observed.

Conclusion: We have confirmed our previously published findings showing that the anorexia nervosa syndrome depends on the hypomotility of the gastrointestinal tract plus hyperglycemia, both of which are triggered by adrenal sympathetic hyperactivity. The above neuroendocrine plus neuroautonomic and clinical disorders which underpinned anorexia nervosa were abruptly suppressed since the first oral dose of amantadine, a drug able to revert the $\mathrm{C} 1(\mathrm{Ad})$ over A5(NA) pontomedullary predominance responsible for adrenal and neural sympathetic activity, respectively.

Keywords: amantadine, anorexia nervosa, adrenal sympathetic activity, hyperglycemia, hyperinsulinism, neural sympathetic activity

\section{Introduction}

We have demonstrated that doxepin, a drug which inhibits the uptake of serotonin (5-HT) is able to normalize patients affected by the hyperinsulinism plus hypoglycemia syndrome. ${ }^{1}$ We have also shown that amantadine, a N-methyl-D-aspartate (glutamate) antagonist, is able to enhance insulin secretion and lower plasma glucagon levels. ${ }^{2-8}$ Considering that both the metabolic and hormonal effects are paralleled by the 
attenuation of neural sympathetic and adrenal sympathetic activity, respectively, we inferred that neuropharmacological drugs able to attenuate the hyperactivity of the $\mathrm{C} 1$ (Ad) medullary nuclei ${ }^{3-8}$ might be powerful tools for treating adrenal sympathetic predominance, including the anorexia nervosa syndrome.

In view of these observations, along with our previous demonstration that the anorexia nervosa syndrome (both restricted type and binge-eating type) is underpinned by maximal adrenal sympathetic overactivity, ${ }^{9}$ we tested the potential therapeutic effects of amantadine, a N-methyl-D-aspartate antagonist that interferes with excitatory glutamate axons at the medullary $\mathrm{C} 1(\mathrm{Ad})$ nuclei in patients affected by this pathophysiological disorder.

\section{Methods}

The study was conducted in accordance with the guidelines of the Declaration of Helsinki. Written informed consent was obtained after the purpose, nature, and potential risks had been explained to the subjects. The experimental protocol was approved by the ethical committee of the Fundación Instituto Medicina Experimental.

\section{Patients}

The study included 22 female patients with anorexia nervosa ( 10 restricted type and 12 binge-eating type) before treatment ${ }^{9}$ and after three months of treatment with amantadine $100 \mathrm{mg} /$ day. The diagnoses were made according to Diagnostic and Statistical Manual of Mental Disorders Fourth Edition criteria. The mean age \pm standard deviation of the patients was $22 \pm 6.4$ years and body weight was $70 \pm 10.1 \%$ of ideal weight, according to Metropolitan Life Insurance Company tables. All patients had been extensively evaluated (physically, endoscopically, radiologically, biochemically, bacteriologically, and immunologically) to rule out any other physical illness, as explained in our previously published study. ${ }^{9}$ Exclusion criteria included pregnancy, lactation, smoking, and alcohol abuse. The patients did not take any medication for 15 days prior to the beginning of the study.

Measurement of blood pressure and heart rate, as well as drawing of blood samples, were performed simultaneously. Supine blood pressure measurements were taken in a standardized fashion using appropriate-sized cuffs and a random-zero mercury sphygmomanometer. All measurements were taken in accordance with a previously published protocol. ${ }^{10}$ Blood samples for plasma neurotransmitter determination were obtained simultaneously with blood pressure and heart rate measurements through a heparinized catheter inserted into the contralateral antebrachial vein 15 minutes before the first blood pressure and heart rate measurements. Plasma noradrenaline, adrenaline, dopamine, free serotonin (f5-HT), and platelet serotonin (p5-HT) levels were assessed during supine resting, one minute of orthostasis, and after five minutes of moderate exercise. All tests were performed on the subjects after 10 hours of fasting. A physician was in constant attendance, and noted any symptoms reported by the subjects.

\section{Analytic methods}

Noradrenaline, adrenaline, dopamine, plasma f5-HT, and p5-HT levels were measured. For all parameters, the samples were assayed in duplicate, and all determinations were made simultaneously. We used reverse-phase, ion-pair highperformance liquid chromatography with electrochemical detection for the measurement of monoamines. Optimization of chromatographic conditions and attainment of adequate quantification parameters allowed us to maximize sensitivity and reproducibility.

Blood for catecholamine and serotonin assays was transferred to plastic tubes, each containing $20 \mathrm{mg}$ of ethylenediamine tetra-acetic acid and $10 \mathrm{mg}$ of sodium bisulfite/mL in solution. The tubes were carefully inverted and placed on ice. The blood was promptly centrifuged at $600 \mathrm{rpm}$ for 15 minutes at $4^{\circ} \mathrm{C}$ in order to obtain platelet-rich plasma. Two milliliters of platelet-rich plasma, obtained for determination of $\mathrm{p} 5$-HT, were taken and stored at $-70^{\circ} \mathrm{C}$ until assayed. The remaining blood was again centrifuged at $7000 \mathrm{rpm}$. The supernatant platelet-poor plasma was divided into two portions for determination of catecholamines and $\mathrm{f5}-\mathrm{HT}$, after which the portions were stored at $-70^{\circ} \mathrm{C}$ until assayed.

\section{Reagents and standards}

Noradrenaline, adrenaline, dopamine, serotonin creatinine sulfate, dihydroxybenzylamine, sodium octyl sulfate, dibutylamine, acid-washed aluminum oxide, $\mathrm{KH}_{2} \mathrm{PO}_{4}$, citric acid, and ethylenediamine tetra-acetic acid were purchased from Sigma-Aldrich (St Louis, MO). Microfilters were purchased from Whatman Inc (Florham Park, NY) through Merck SA, (Caracas, Venezuela). Acetonitrile and 2-propanol were obtained from Merck SA. Glass-distilled water was deionized and filtered through a Millipore Milli-Q reagent grade water system (Bedford, MA). Solvents were filtered through a $0.2 \mu \mathrm{m}$ Millipore filter and were vacuum deaerated. Standard solutions $(1 \mathrm{mmol} / \mathrm{L})$ were prepared in $0.1 \mathrm{~mol} / \mathrm{L}$ perchloric acid and diluted to the desired concentration. 


\section{Equipment}

Liquid chromatography was performed using a Waters 515 HPLC pump (Waters Corporation, Milford, MA) equipped with a Rheodyne valve injector $7125 \mathrm{i}$, which was fitted with a $50 \mu \mathrm{L}$ sample loop (Rheodyne, Berkeley, CA). A $15 \mathrm{~cm} \times 4.6 \mathrm{~mm}$ inner diameter Discovery $\mathrm{C} 18$ column packed with octadecyl silane $5 \mu \mathrm{m}$ particles was preceded by a column prefilter of $2 \mu \mathrm{m}$ porosity, both from Supelco/Sigma-Aldrich. The detection system was a 460 electrochemical detector (Waters Corporation). The potential of the glass carbon working electrode was set at $\pm 0.61 \mathrm{~V}$ versus the $\mathrm{Ag}$ - $\mathrm{AgCl}$ reference electrode for detection of catecholamines and $0.70 \mathrm{~V}$ versus the $\mathrm{Ag}-\mathrm{AgCl}$ for detection of indolamines. The chromatograms were registered and quantified using Empower software (Waters Corporation). The results were corrected for the volume of ethylenediamine tetra-acetic acid added.

\section{Analytical assays}

\section{Plasma catecholamines}

The assay was performed by extraction of the catecholamines onto $20 \mathrm{mg}$ of alumina followed by elution with $200 \mu \mathrm{L}$ of $1.0 \mathrm{~mol} / \mathrm{L} \mathrm{HClO}_{4}$ using regenerated cellulose microfilters of $0.2 \mu \mathrm{m}$ pore size purchased from Whatman Inc (Piscataway, NJ). We calibrated the instrument with standard plasma. After incubation with acid-washed aluminum oxide, a plasma pool of free catecholamines was processed similarly to the plasma samples, but $20 \mu \mathrm{L}$ of a standard solution of noradrenaline, adrenaline, and dopamine $(50,25$, and $25 \mathrm{ng} / \mathrm{mL}$, respectively) was added to the plasma pool. Both the standard plasma and the sample plasma were supplemented with $20 \mu \mathrm{L}$ of internal standard (dihydroxybenzylamine $100 \mathrm{ng} / \mathrm{mL}$ ). The mobile phase was $\mathrm{KH}_{2} \mathrm{PO}_{4} 6.8045 \mathrm{~g} / \mathrm{L}$, ethylenediamine tetraacetic acid $0.1 \mathrm{~g} / \mathrm{L}$, and di-N-butylamine $100 \mu \mathrm{L} / \mathrm{L}$. Sodium octyl sulfate was added as an ion-pair agent at a concentration of $0.6125 \mathrm{~g} / \mathrm{L}$, with the $\mathrm{pH}$ adjusted to 5.6. The flow rate was $0.4 \mathrm{~mL} / \mathrm{min}$. The sensitivities of this method for noradrenaline, adrenaline, and dopamine, were $6.4,5.8$, and $2.0 \mathrm{pg} / \mathrm{mL}$, respectively. The intra-assay coefficients of variation were $2.8,4.0$, and $4.0 \%$, respectively. The interassay coefficients of variation were $6.7,4.5$, and $4.3 \%$, respectively.

\section{Plasma indolamines}

After sonication of platelet-rich plasma to disrupt the platelets (Ultrasonic Liquid Processor, Model 385; Heat Systems Ultrasonics Inc, Farmingdale, NY), both platelet-rich and platelet-poor plasma samples were processed in the same way, ie, $200 \mu \mathrm{L}$ of $3.4 \mathrm{~mol} / \mathrm{L}$ perchloric acid and $50 \mu \mathrm{L}$ of 5-hydroxytryptophan solution $(114.5 \mu \mathrm{g} / \mathrm{mL})$ as the internal standard, were added to $1 \mathrm{~mL}$ of plasma vortexed and centrifuged at $10,000 \mathrm{rpm}$ for 15 minutes at $4{ }^{\circ} \mathrm{C}$. The supernatant was filtered through a $0.22 \mu \mathrm{m}$ membrane (Millipore) and $10 \mu \mathrm{L}$ was injected into the column. Calibration runs were generated by spiking blank plateletpoor plasma with $50 \mu \mathrm{L}$ of a solution containing 5-HT $10 \mu \mathrm{g} / \mathrm{mL}$ ) and $50 \mu \mathrm{L}$ of $5-\mathrm{HT} 114.5 \mu \mathrm{g} / \mathrm{mL}$. This standard plasma was processed in the same manner as the samples. The mobile phase was citric acid $3.8424 \mathrm{~g} / \mathrm{L}$, sodium acetate $4.1015 \mathrm{~g} / \mathrm{L}$, ethylenediamine tetra-acetic acid $0.100 \mathrm{~g} / \mathrm{L}$, di-N-butylamine $100 \mu \mathrm{L} / \mathrm{L}$, and $30 \mathrm{~mL} / \mathrm{L}$ of 2-propanol. Sodium octyl sulfate was added as an ion-pair agent at a concentration of $4.25 \mathrm{mg} / \mathrm{L}$, with a $\mathrm{pH}$ of 5.0. The flow rate was $0.610 \mathrm{~mL} / \mathrm{min}$. The sensitivity of the method for serotonin was $0.1 \mathrm{ng} / \mathrm{mL}$. The intra-assay coefficients of variation for p5-HT and f5-HT were 6.2 and $8.7 \%$, respectively.

\section{Statistical methods}

The results are presented as the mean \pm standard error of measurement. Multivariate one-way analysis of variance with repeated measurements, and correlation coefficients (exploratory factor analysis) were used. Dbase Stats ${ }^{\mathrm{TM}}$ by Ashton Tate and Statview SE \pm Graphics by Abacus were used for the statistical analysis.

\section{Results}

We have previously demonstrated that there are no significant neuroendocrine or neuroautonomic differences between the two clinical types of anorexia nervosa, ie, the restricted and binge-eating types. ${ }^{9}$

\section{Cardiovascular parameters}

Neither systolic nor diastolic blood pressure showed significant variations during orthostasis or after moderate exercise in our patients. However, differential pressure showed a significant increase during orthostasis before but not after amantadine treatment. Heart rate showed significant and progressive rises during both orthostasis and exercise periods before but not after amantadine treatment (Table 1).

\section{Catecholamines}

Plasma noradrenaline showed significant and progressive increases during orthostasis and exercise in the two groups. However, the noradrenaline values and their increases were significantly higher after amantadine therapy. In addition, adrenaline showed important and significant increases during orthostasis and exercise in the patients before treatment but not in treated patients. Plasma dopamine levels showed a 
Table I Systolic, diastolic blood pressure, heart rate, noradrenaline, adrenaline, dopamine, platelet serotonin, and free blood serotonin blood values, at 0 minutes (resting), one minute (orthostasis), and five minutes (postexercise) in 22 patients with anorexia nervosa during a symptomatic period and during an asymptomatic period three months after treatment with amantadine $100 \mathrm{mg} / \mathrm{day}$

\begin{tabular}{|c|c|c|c|c|c|c|}
\hline & \multirow[t]{2}{*}{$0 \mathrm{~min}$} & \multirow[t]{2}{*}{$I \min$} & \multirow[t]{2}{*}{$5 \mathrm{~min}$} & \multicolumn{3}{|l|}{$P$ values } \\
\hline & & & & $\mathbf{0}$ vs I $\mathrm{min}$ & 0 vs 5 min & I vs $5 \mathrm{~min}$ \\
\hline SBP ANs & $152 \pm 5$ & $15 \pm 3$ & $17 \pm 6$ & $<0.05^{*}$ & $<0.02^{*}$ & $<0.02^{*}$ \\
\hline $\mathrm{ANa}$ & $120 \pm 3$ & $12 \pm 4$ & $13 \pm 6$ & ns & ns & ns \\
\hline DBP ANs & $60 \pm 3$ & $60 \pm 2$ & $61 \pm 3$ & ns & ns & ns \\
\hline $\mathrm{ANa}$ & $74 \pm 4$ & $70 \pm 4$ & $76 \pm 6$ & ns & ns & ns \\
\hline HR ANs & $71 \pm 3$ & $79 \pm 4$ & $83 \pm 6$ & $<0.02 * *$ & $<0.0 \mathrm{I} * *$ & $<0.01 * *$ \\
\hline $\mathrm{ANa}$ & $66 \pm 6$ & $64 \pm 4$ & $74 \pm 6$ & ns & ns & ns \\
\hline NA ANs & $166 \pm 4$ & $169 \pm 5$ & $175 \pm 5$ & ns & ns & ns \\
\hline $\mathrm{ANa}$ & $186 \pm 6$ & $214 \pm 8$ & $235 \pm 7$ & $<0.05^{*}$ & $<0.01 * *$ & $<0.01 * *$ \\
\hline Ad ANs & $52 \pm 2$ & $67 \pm 3$ & $84 \pm 4$ & $<0.05^{*}$ & $<0.00 I^{* * *}$ & $<0.00 I^{* * * *}$ \\
\hline $\mathrm{ANa}$ & $27 \pm 5$ & $30 \pm 4$ & $35 \pm 3$ & ns & ns & ns \\
\hline DA ANs & $18 \pm 1$ & $21 \pm 2$ & $23 \pm 2$ & ns & ns & $<0.05^{*}$ \\
\hline $\mathrm{ANa}$ & $15 \pm 4$ & $20 \pm 4$ & $22 \pm 5$ & ns & ns & ns \\
\hline p5-HT ANs & $228 \pm 19$ & $249 \pm 22$ & $225 \pm 25$ & ns & ns & ns \\
\hline $\mathrm{ANa}$ & $258 \pm 31$ & $316 \pm 27$ & $308 \pm 32$ & ns & ns & ns \\
\hline f5-HT ANs & $3.2 \pm 1$ & $13.7 \pm 1$ & $24.5 \pm 2$ & $<0.001 * * *$ & $<0.001 * * *$ & $<0.001 * * *$ \\
\hline $\mathrm{ANa}$ & $2.1 \pm 1$ & $2.3 \pm 1$ & $3.1 \pm 1$ & ns & ns & ns \\
\hline
\end{tabular}

Notes: Values are mean \pm standard error of the mean. $* P<0.05$; $* * P<0.02$; $* * * P<0.001$.

Abbreviations: $\mathrm{ANa}$, asymptomatic of anorexia nervosa; ANs, symptomatic of anorexia nervosa; $\mathrm{DBP}$, diastolic blood pressure (mmHg); SBP, systolic blood pressure $(\mathrm{mmHg}) ; \mathrm{HR}$, heart rate (beats/min); NA, noradrenaline ( $\mathrm{pg} / \mathrm{mL})$; Ad, adrenaline (pg/mL); DA, dopamine (pg/mL); $\mathrm{p} 5-\mathrm{HT}$, platelet serotonin (ng/mL); f5-HT, free serotonin (ng/mL); ns, not significant.

significant increase during orthostasis in nontreated patients but not in treated patients.

\section{Indolamines}

p5-HT did not show any significant variation before or after treatment. Plasma f5-HT, (ie, outside the platelets) showed mean basal values which were greater before treatment and showed progressive and significant decreases after amantadine treatment. Significant correlations between the different physiologic and neurochemical variables during rest, orthostasis, and after moderate exercise are shown in Table 2.

\section{Discussion}

Our results show that a low dose (100 mg/day) of amantadine, a drug which abruptly suppresses adrenal sympathetic activity, ${ }^{9,11}$ was able to abolish symptoms of anorexia nervosa in 22 affected patients when it was administered 45 minutes before the main meal, and also when it was administered 45 minutes before an oral glucose tolerance test (manuscript in preparation). Patients were able to eat all types of foods and recovered their normal body weight. Normalization of cardiovascular parameters (enhancement of diastolic blood pressure and reduction of systolic blood pressure and heart rate) were registered in all cases. Namely, the present research confirms that the anorexia nervosa syndrome is underpinned by an overwhelming predominance of adrenal sympathetic branch activity which abrogates neural sympathetic activity. This pathophysiological disorder includes symptoms at all levels (cardiovascular, digestive, metabolic, endocrine, respiratory, etc), as well as psychological and neuroautonomic disturbances.

Understanding of the pathophysiology of anorexia nervosa syndrome requires knowledge about hyperactivity of the adrenal sympathetic branch ${ }^{9,12,13}$ which is responsible for gastrointestinal hypoactivity, ${ }^{9,14-17}$ systolic blood pressure and heart rate enhancement, hyperglycemia, tracheobronchial dilation + hypersecretion, and anxiety. ${ }^{18}$ Neuroendocrine and metabolic disorders should also be included into this syndrome, the source of which is located at the medullary C1(Ad) nuclei responsible for the peripheral adrenal sympathetic branch. ${ }^{19,20}$ The findings presented in this study demonstrate also that an oral dose of amantadine, a N-methyl-D-aspartate antagonist which annuls the firing activity of the C1(Ad) medullary nuclei, ${ }^{11}$ minimizes systolic blood pressure and heart rate, both of which are cardiovascular parameters positively correlated with adrenal sympathetic activity. The recovery of gastrointestinal motility and normal feeding were paralleled by a body weight increase. These clinical and physiological parameters 
Table 2 Significant correlations for physiological and plasma neurotransmitter parameters at 0 minutes (resting), one minute (orthostasis), and five minutes (postexercise) in 22 patients with anorexia nervosa during a symptomatic pretreatment period and during an asymptomatic period three months after treatment with amantadine $100 \mathrm{mg} / \mathrm{day}$

\begin{tabular}{|c|c|c|c|c|c|c|c|c|}
\hline & SBP & DBP & HR & NA & Ad & DA & p5-HT & $\overline{\mathrm{f5}-\mathrm{HT}}$ \\
\hline \multicolumn{9}{|c|}{ ANs 0 min } \\
\hline HR & $0.6 I^{*}$ & & & & & & & \\
\hline Ad & $0.66 *$ & & $0.70 *$ & & & & & \\
\hline DA & & & & & $0.64 *$ & & & \\
\hline f5-HT & & & $0.70^{*}$ & & $0.70 *$ & & & \\
\hline \multicolumn{9}{|c|}{ ANa $0 \mathrm{~min}$} \\
\hline$H R$ & $0.63^{*}$ & & & & & & & \\
\hline \multicolumn{9}{|c|}{ ANs I min } \\
\hline HR & $0.60 *$ & & & & & & & \\
\hline Ad & $0.60 *$ & & $0.69 * *$ & & & & & \\
\hline DA & & & & & $0.63 * *$ & & & \\
\hline f5-HT & & & $0.60^{*}$ & & $0.69 *$ & & & \\
\hline \multicolumn{9}{|c|}{ ANa I min } \\
\hline Ad & & & $0.63^{*}$ & & & & & \\
\hline \multicolumn{9}{|c|}{ ANs $5 \mathrm{~min}$} \\
\hline HR & $0.70 * *$ & & & & & & & \\
\hline Ad & $0.75^{* *}$ & & $0.80 * * *$ & & & & & \\
\hline f5-HT & & & $0.66 *$ & & $0.68 *$ & & & \\
\hline
\end{tabular}

Notes: $* p<0.05 ; * * p<0.02 ; * * * p<0.001$.

Abbreviations: $\mathrm{ANa}$, asymptomatic of anorexia nervosa; $\mathrm{ANs}$, symptomatic of anorexia nervosa; $\mathrm{DBP}$, diastolic blood pressure ( $\mathrm{mmHg}$ ); $\mathrm{SBP}$, systolic blood pressure (mmHg); $\mathrm{HR}$, heart rate (beats/min); NA, noradrenaline ( $\mathrm{pg} / \mathrm{mL})$; Ad, adrenaline $(\mathrm{pg} / \mathrm{mL})$; DA, dopamine $(\mathrm{pg} / \mathrm{mL})$; $\mathrm{p} 5-\mathrm{HT}$, platelet serotonin $(\mathrm{ng} / \mathrm{mL})$; f5-HT, free serotonin $(\mathrm{ng} / \mathrm{mL})$.

were paralleled by normalization of the insulin versus glucagon balance throughout the oral glucose tolerance test. ${ }^{2}$

The dramatic therapeutic effect triggered by amantadine supports our hypothesis that the drug acts through central nervous system mechanisms. With respect to this, we now summarize some information dealing with this issue. The C1(Ad) medullary and the A5(NA) pontine nuclei are the motor centers of the adrenal and neural sympathetic branches of the peripheral autonomic system, respectively. ${ }^{3-8}$ Glutamate axons excite the former but not the latter nuclei. However, both nuclei interchange inhibitory axons which act at postsynaptic alpha-2 inhibitory receptors. ${ }^{3-8}$ The $\mathrm{C} 1$ (Ad) nuclei send polysynaptic drives to both pancreatic A cells (secreting glucagon) and to the adrenal glands (secreting adrenaline). ${ }^{21}$ Conversely, A5(NA) neurons send polysynaptic drives to the lumbar sympathetic neurons which excite sympathetic ganglia (whose axons release noradrenaline preferentially and dopamine). In addition, insulin released from B cells crosses the blood-brain barrier and excites the A5(NA) neurons, ${ }^{3-5,22-25}$ whereas glucagon secreted from $A$ cells crosses the blood-brain barrier and excites the $\mathrm{C} 1(\mathrm{Ad})$ nuclei. ${ }^{26-30}$

Circulating insulin triggers hypoglycemia and enhances gastrointestinal motility and feeding, whereas glucagon provokes hyperglycemia and abrogates gastrointestinal motility, both of which are factors responsible for anorexia. . $, 9,19,23,31^{2}$
This central and autonomic neuroendocrine interaction facilitates the understanding of the dramatic annulment of anorexia nervosa syndrome provoked by a small oral dose of amantadine, a drug that interrupts the central nervous system C1(Ad) and A cell (glucagon) crosstalk.

Some additional information should facilitate the understanding of the above issue. We were able to demonstrate that insulin crosses the blood-brain barrier and excites the noradrenergic neurons responsible for peripheral neural sympathetic activity, ${ }^{22}$ and our findings have been confirmed by other authors. ${ }^{25}$ Furthermore, we have also demonstrated that postprandial hypoglycemia and hyperinsulinism are provoked by the predominance of this sympathetic branch. Furthermore, we found that neuropharmacological manipulation to attenuate the neural sympathetic predominance was able to normalize this postprandial hypoglycemia and hyperinsulinism disorder. ${ }^{1,23}$ These findings are now complemented by the results presented here, showing that the anorexia nervosa syndrome is located on the opposite "side of the coin", namely, adrenergic hyperactivity and hyperglycemia, which may be abrogated by adequate neuropharmacological manipulation.

\section{Disclosure}

The authors report no conflicts of interest in this work. 


\section{References}

1. Lechin F, van der Dijs B, Lechin A, et al. Doxepin therapy for postprandial symptomatic hypoglycemic patients: Neurochemical, hormonal and metabolic disturbances. Clin Sci. 1991;80:373-384.

2. Lechin F, van der Dijs B, Pardey Maldonado B, Rivera JE, Lechin ME, Baez S. Amantadine reduces glucagon and enhances insulin secretion throughout the oral glucose tolerance: Central plus peripheral nervous system mechanisms. Diabetes Metab Syndr Obes. 2009;2:203-213.

3. Elenkov IJ, Wilder RL, Chrousos GP, Vizi EZ. The sympathetic nerve - an integrative interface between two supersystems: The brain and the immune system. Pharmacol Rev. 2000;52:595-638.

4. Maiorov DN, Wilton ER, Badoer E, Petrie D, Head GA, Malpas SC. Sympathetic response to stimulation of the pontine A5 region in conscious rabbits. Brain Res. 1999;815:227-236.

5. Byrum CE, Guyenet PG. Afferent and efferent connections of the A5 noradrenergic cell group in the rat. J Comp Neurol. 1987; 261:529-542.

6. Dampney RA. Functional organization of central pathways regulating the cardiovascular system. Physiol Rev. 1994;74:323-364.

7. Li YW, Wesselingh SL, Blessing WW. Projections from rabbit caudal medulla to $\mathrm{C} 1$ and A5 sympathetic premotor neurons, demonstrated with phaseolus leucoagglutinin and herpes simplex virus. J Comp Neurol. 1992;317:379-395.

8. Reis DJ, Ruggiero DA, Morrison SF. The $\mathrm{C} 1$ area of the rostralventrolateral medulla oblongata. A critical brainstem region for control of resting and reflex integration of arterial pressure. Am J Hypertens. 1989;2:363S-374S.

9. Lechin F, van der Dijs B, Pardey-Maldonado B, Rivera JE, Baez S, Lechin ME. Anorexia nervosa depends on adrenal sympathetic hyperactivity: Opposite neuroautonomic profile of hyperinsulinism. Diabetes Metab Syndr Obes. 2010;3:311-317.

10. Lechin F, van der Dijs B, Orozco B, et al. Plasma neurotransmitters, blood pressure and heart rate during supine-resting, orthostasis and moderate exercise conditions in major depressed patients. Biol Psychiatry. 1995;38:166-173.

11. Lechin F, van der Dijs B, Pardey-Maldonado B, Rivera JE, Baez S, Lechin ME. Effects of amantadine on circulating neurotransmitters in healthy subjects. J Neural Transm. 2010;117:293-299.

12. Støving RK, Hangaard J, Hansen-Nord M, Hagen C. A review of endocrine changes in anorexia nervosa. J Psychiatr Res. 1999;33:139-152.

13. Kaye WH, Ebert MH, Raleigh M, Lake R. Abnormalities in CNS monoamine metabolism in anorexia nervosa. Arch Gen Psychiatry. 1984;41:350-355.

14. Nagata M, Osumi Y. Central noradrenergic inhibition of gastric motility in rats. Eur J Pharmacol. 1992;223:153-156.

15. Landsberg L, Young JB. Fasting, feeding and regulation of the sympathetic nervous system. N Engl J Med. 1978;298:1295-1301.
16. Ritter RC, Epstein AN. Control of meal size by central noradrenergic action. Proc Natl Acad Sci U S A. 1975;72:3740-3743.

17. Booth DA. Localization of the adrenergic feeding system in the rat diencephalon. Science. 1967;158:515-517.

18. Godart NT, Flament MF, Lecrubier Y, Jeammet P. Anxiety disorders in anorexia nervosa and bulimia nervosa: Co-morbidity and chronology of appearance. Eur Psychiatry. 2000;15:38-45.

19. Lechin F, van der Dijs B. Central nervous system plus autonomic nervous system disorders responsible for the gastrointestinal and pancreatobiliary diseases. Dig Dis Sci. 2009;54:458-470.

20. Lechin F, van der Dijs B. Central nervous system circuitries underlying two types of peripheral autonomic nervous system disorders. Open Neurosci J. 2008;2:41-50.

21. Loewy AD, Franklin MF, Haxhiu MA. CNS monoamine cell groups projecting to pancreatic vagal motor neurons: A transneuronal labeling study using pseudorabies virus. Brain Res. 1994;638:248-260.

22. Lechin F, van der Dijs B, Lechin M, et al. Effects of an oral glucose load on plasma neurotransmitters in humans: Involvement of REM sleep? Neuropsychobiology. 1992;26:4-11.

23. Lechin F, van der Dijs B. Central nervous system (CNS) circuitry involved in the hyperinsulinism syndrome. Neuroendocrinology. 2006; $84: 222-234$

24. Christensen NJ. Acute effects of insulin on cardiovascular function and noradrenaline uptake and release. Diabetologia. 1983;25: 377-381.

25. Fisher SJ, Brüning JC, Lannon S, Kahn CR. Insulin signaling in the central nervous system is critical for the normal sympathoadrenal response to hypoglycemia. Diabetes. 2005;54:1447-1451.

26. Abdelmelek H, Fechtali T, Filali-Zegzouti Y, et al. Responsiveness of plasma catecholamines to intracerebroventricualr injection of glucagon in muscovy ducklings. J Neural Transm. 2001;108:793-801.

27. Strack AM, Sawyer WB, Platt KB, Loewy AD. CNS cell groups regulating the sympathetic outflow to adrenal gland as revealed by transneuronal cell body labeling with pseudorabies virus. Brain Res. 1989;491:274-296.

28. Strack AM, Sawyer WB, Hughes JH, Platt KB, Loewy AD. A general pattern of CNS innervation of the sympathetic outflow demonstrated by transneuronal pseudorabies viral infections. Brain Res. 1989;491:156-162.

29. Strack AM, Loewy AD. Pseudorabies virus: A highly specific transneuronal cell body marker in the sympathetic nervous system. J Neurosci. 1990;10:2139-2147.

30. Gerendai I, Halász B. Central nervous system structures connected with the endocrine glands. Findings obtained with the viral transneuronal tracing technique. Exp Clin Endocrinol Diabetes. 2000;108: 389-395.

31. Lechin F, van der Dijs B, Pardey-Maldonado B. Insulin versus glucagon: Central plus peripheral mechanisms. Am J Ther. 2011. In press.
Therapeutics and Clinical Risk Management

\section{Publish your work in this journal}

Therapeutics and Clinical Risk Management is an international, peerreviewed journal of clinical therapeutics and risk management, focusing on concise rapid reporting of clinical studies in all therapeutic areas, outcomes, safety, and programs for the effective, safe, and sustained use of medicines. This journal is indexed on PubMed Central, CAS,

\section{Dovepress}

EMBase, Scopus and the Elsevier Bibliographic databases. The manuscript management system is completely online and includes a very quick and fair peer-review system, which is all easy to use. Visit $\mathrm{http}: / /$ www.dovepress.com/testimonials.php to read real quotes from published authors. 